\title{
Evaluation of Optical Methods of Detecting Dental Pulp Vitality
}

\author{
Michael E. Fein, ${ }^{\dagger}$ Alan H. Gluskin, ${ }^{\dagger}$ William W. Y. Goon, ${ }^{\dagger}$ Bradford B. Chew ${ }^{\dagger}$ \\ Willem A. Crone, ${ }^{\dagger}$ and Henry W. Jones ${ }^{*}$ \\ ${ }^{\dagger}$ Nellcor Puritan Bennett, Inc., 4280 Hacienda Drive, Pleasanton, California 94588; ${ }^{\star}$ University of \\ the Pacific, School of Dentistry, Department of Endodontics, 2155 Webster Street, San \\ Francisco, California 94115; 1050/78 Borregas Avenue, Sunnyvale, California 94089 \\ (Paper JBO-099 received June 28, 1996; revised manuscript received Sep. 27, 1996; accepted for publication Sep. 30, 1996.)
}

\begin{abstract}
An attempt to develop an optical probe to assess dental pulp vitality led to the conclusion that it would be difficult to construct an effective optical probe for the middle-aged and older patient who is a common candidate for pulpal assessment. In such patients, vascularity of the gingiva is so much greater than that of the pulp that signals originating in the gingiva overwhelm pulpal effects. This conclusion applies to photoplethysmography, pulse oximetry, and laser Doppler flowmetry, and probably to spectrophotometry as well. The effect of the gingiva was first demonstrated by placing opaque plastic film in the gingival sulcus, which caused attenuation of light passing through molar and bicuspid teeth. More dramatically, the remaining pulsatile signal could be much further attenuated by vasoconstricting the gingiva. An unusually sensitive photoplethysmograph was developed (noise floor, with signal averaging, was near $10 \mathrm{fA}$ ), as were a variety of optical probes (including two that approached the tooth below the gingival margin). The tools, methods, and conceptual models that were developed are intended also to be of use to investigators who are developing optical probes for use in younger subjects, in whom such probes appear to be useful. ( $) 1997$ Society of Photo-Optical Instrumentation Engineers.
\end{abstract}

Keywords dental pulp vitality; photoplethysmography; laser Doppler flowmetry; pulse oximetry; spectrophotometry; fiber optics.

\section{INTRODUCTION}

There has long been interest in using optical methods to determine the vitality of the dental pulp as a baseline indicator of pulpal health and a guide to the feasibility of restorative procedures. We report here the results of an effort to develop a very sensitive optical vitality probe and to determine whether the clear signals produced by such a probe originate in the dental pulp.

Optical testing is interesting for several reasons:

- Most optical methods attempt to evaluate the circulatory status of the pulp, as opposed to the condition of the nerves terminating in the pulp. It is known ${ }^{1}$ that the pulp of a traumatized tooth can be vital even when neural stimulation methods fail, and that after some time for repair, neural response may reappear.

- The widely accepted pulp testing methods (heat test, cold test, and electrical stimulation) are only moderately reliable in diagnosis of pulpal health. ${ }^{2}$ An optical probe, simply because it measures something different, may be diagnostically useful in combination with traditional pulp testing methods.

Address technical correspondence to Michael E. Fein (E-mail: michael.fein@nellcorpb.com) or to Alan H. Gluskin; reprint requests to Prof. Gluskin.
- Pulp testing involves at least the threat and often the reality of pain. Optical methods are inherently painless, except to the extent that any mechanical contact with the tooth may be painful for certain patients.

\subsection{PHOTOPLETHYSMOGRAPHY AND PULSE OXIMETRY}

The photoplethysmograph senses bloodflowinduced pulsations in the optical transmission of tissue. Its use to observe pulses in the teeth of dogs was reported by Upthegrove, ${ }^{3}$ and in the teeth of humans by Kobo (Ref. 4, cited in Ref. 5). Other early dental applications of the photoplethysmograph and the pulse oximeter are cited by Schmitt, Webber, and Walker. ${ }^{6}$ Additional references to dental photoplethysmography appear in Ikawa, Horiuchi, and Ikawa.? There is a perception among pulp biologists that "the photoplethysmograph's signal...is too weak and difficult to interpret for this technique to be a reliable means to measure pulp blood flow." ${ }^{\prime 8}$ We believed that modern electronic techniques could overcome the weakness of the plethysmographic signal, so that if the needed information were physiologically present, the simpler 
and less expensive plethysmograph might be preferable to the more commonly used laser Doppler flowmeter (LDF).

A first-order explanation of the operation of the photoplethysmograph begins with the contraction of the heart forcing a transient increase in the amount of blood in the arterioles. The distended arterioles discharge their excess volume of blood into the capillaries and veins during the diastolic phase of the heartbeat. If such changes in the proportion of blood in tissue were the only way a photoplethysmograph could work, there would be little point in trying to measure blood flow in teeth by this method, because the pulp space is a rigidly enclosed volume, with low compliance to increases in hydrostatic pressure. ${ }^{9}$ The soft tissue of the pulp is largely water, which is as incompressible as the surrounding dentin. Nonetheless, many authors report the detection of pulses from teeth, and pulses can be detected by an optical plethysmograph looking at blood moving in a rigid glass tube. ${ }^{10-12}$ If the photoplethysmograph can truly detect pulses in teeth, it must be through a "second-order" effect, such as changes in optical transmission of blood vessels caused by redistribution of red cells closer to the vessel axis when the blood is moving, or by change in orientation of the platelike cells as they surge in the arteriole.

A pulse oximeter is a two-wavelength optical plethysmograph. Pulses are observed at two wavelengths (one red and one near-infrared), and from the details of these pulses it is possible to compute the fraction of hemoglobin in the moving arterial blood which is bound to oxygen. ${ }^{13}$

We chose to concentrate our efforts on the simple single-wavelength photoplethysmograph, bypassing the additional problems of interpretation of pulse oximeter results that are caused by light rays that scatter through the tooth without contacting the pulp (see ray 2 in Figure 1).

Ray 3 in Figure 1 suggests that even a simple photoplethysmograph may be confused by spurious rays that pass through the gingiva instead of through the pulp. The experiments discussed in this paper showed that such rays are of great importance.

Implicit in the jagged ray paths shown in Figure 1 is the belief that scattering events cause photons to lose all memory of their initial direction of propagation by the time they have traveled a distance on the order of $1 \mathrm{~mm}$ in enamel or dentin. ${ }^{14-17}$ In other words, soon after entering the tooth, rays are traveling in completely random directions. Visual observation in a darkened room supports this beliefteeth illuminated by lasers or light-emitting diodes (LEDs) light up all over.

\subsection{LASER DOPPLER FLOWMETER}

The $\mathrm{LDF}^{18}$ is a well-developed tool for characterizing near-surface circulation. Gazelius et al. ${ }^{19}$ re-

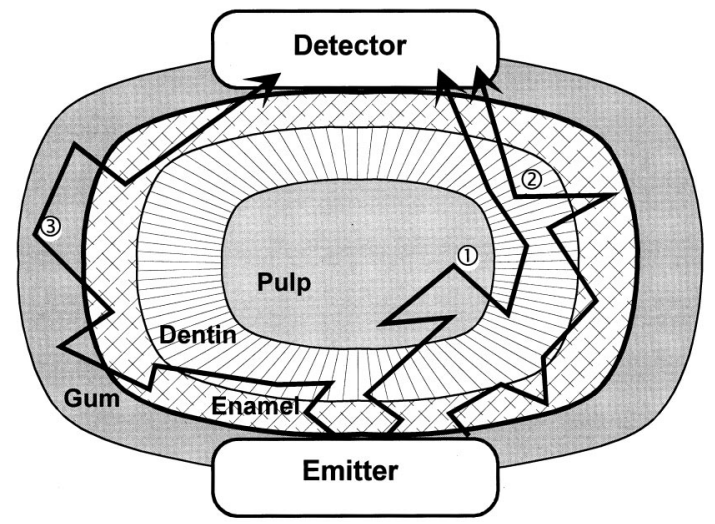

Fig. 1 Spurious light rays can confuse photoplethysmographs and pulse oximeters. Ray 1 passes through the pulp. It may carry useful information about pulse amplitude or oxygenation. Ray 2 misses the pulp. It would cause error in a pulse oximeter. Ray 3 passes through the gingiva. It would provide misleading information to any instrument studying the pulp.

ported its use to observe the dental pulp. A specialized hand-held instrument for dental application was described by Pettersson and Öberg. ${ }^{20}$ Olgart ${ }^{21}$ has reviewed the literature associated with use of the LDF for pulp testing. The LDF depends for its operation upon the Doppler shift, a small change in the frequency of light that scatters from a moving red blood cell. The frequency shift can be observed by mixing the frequency-shifted light on a photocell with light that has bounced off nonmoving parts of the tissue, and which therefore has not shifted in frequency. The so-called "heterodyne effect" is the appearance in the output of the photocell of an electrical signal whose frequency is the difference between the frequencies of shifted and unshifted light rays. The frequency of this ac electrical signal is a measure of the velocity of the moving red blood cells, and its amplitude is a measure of the concentration of cells that are moving.

\section{OPTICS AND MECHANICS}

The dental dam clamp, in its current evolution, is an admirable work of mechanical design. Inexpensive, simple, quick to apply, it provides a stable mechanical base on the variably shaped, often slippery surface of the tooth. An optical probe intended for routine clinical use requires the same characteristics. We have made some progress toward this design goal in developing several tools for subgingival and supragingival optical testing.

Many of the teeth presented to dentists for potential treatment have their visible surfaces partially or fully obscured by restorations. To be most useful to the practitioner, an optical tool should be able to transmit and receive light under the edge of an opaque full crown. This principle was recognized by Schnettler and Wallace, ${ }^{22}$ but we know of no previous practical realizations of a subgingival optical probe addressing the tooth. We demonstrated 


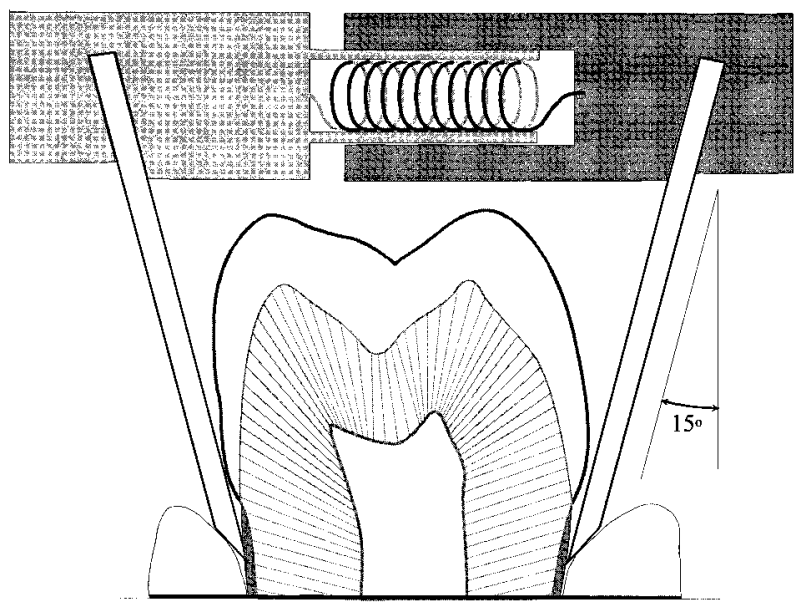

Fig. 2 Cutaway view of the first subgingival probe.

two such probes. The first of these (see Figure 2) applied $3.5 \times 1 \mathrm{~mm}$ injection-molded polystyrene light guides (shown schematically in Figure 3 ) to opposite faces of the tooth. Light was delivered to one guide by a glass fiber optic bundle. A passivated unencapsulated silicon photodetector chip (Advanced Photonix, Inc., Camarillo, California), prepared by the vendor with soldered-on wire leads, was attached directly to the top of the other light guide.

The light guides were sputter metallized with silver to avoid optical leakage through the slanted reflector at the bottom of the guide. The metallization was overcoated with black epoxy resin (Epo-tek 320, thinned with acetone; Epoxy Technology, Inc., Billerica, Maine) to seal pinholes, then overcoated for durability with the same clear epoxy (Epo-tek 301) that was used to butt seal the afferent fiber optic illumination channel to the light guide. After insulating the glued-on detector chip with a layer of epoxy, we connected it to a shielded twisted-pair electrical cable and applied a copper-foil shield

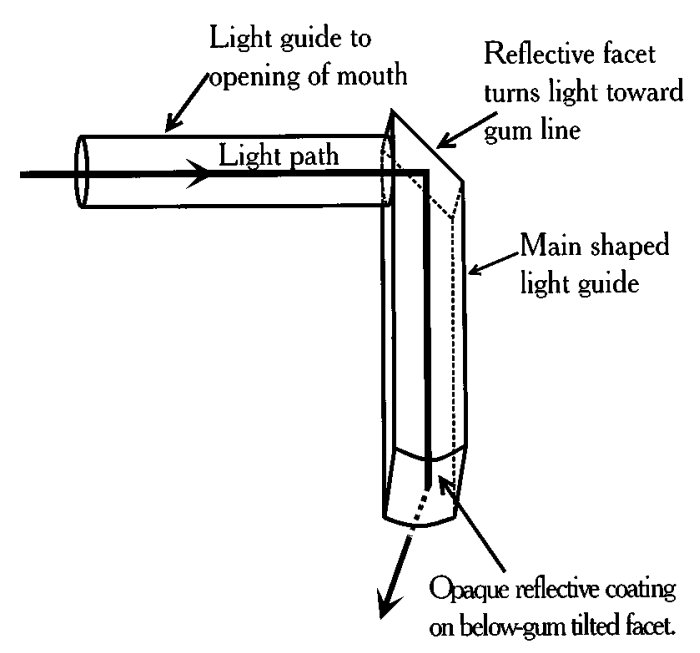

Fig. 3 Light-pipe configuration for a subgingival probe.
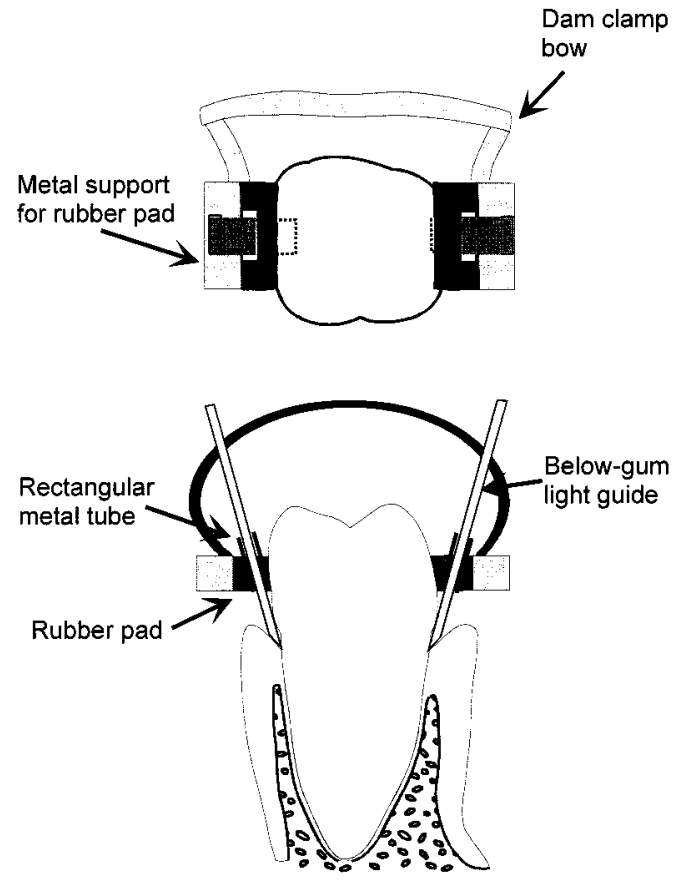

Fig. 4 Schematic diagram of a below-gum probe with rubber pads for lateral stabilization.

over the chip and the short sections of lead wire that remained exposed between the chip and the cable shield.

Optical efficiency was poor, but this device proved the feasibility of detecting pulses with a subgingival probe. The clinicians on our team found the probe easy to slide into position on the tooth. The tapered end, tipped back at $15 \mathrm{deg}$ from the axis of the clip, slipped easily into the gingival sulcus. Spring action caused the probe to pull itself down into position until the ends of the light guides contacted the nearly vertical cementum surfaces of the tooth. Test subjects found it only slightly uncomfortable.

A key concern in designing the subgingival probe was the contour of the tooth surface at the point of gingival attachment. Both of the middle-aged subjects on whom the initial subgingival probe was tested had attachment points far enough onto the cementum so that the natural tendency of the spring clip to pull itself down onto the tooth would stop before the light guide encroached upon the bottom of the sulcus. In a younger patient having a higher gingival attachment, the soft tissue would lack this protection. We therefore developed a second design, shown in Figure 4, in which the optical probe could be positioned independently of the location of the supporting structure, and in which the clinician could use tactile feedback to place the probe accurately. This design had the further advantage that it would accommodate different sulcular heights on lingual and facial surfaces of a tooth. A metal spring clip, made by molding wide elastomeric pads onto the bow of a dental dam clamp, 
provided a stable mount on the tooth. This clip, which was applied with dam clamp pliers, supported a molded elastomer structure containing rectangular metal tubes in which light guides were supported. With the clip applied to the tooth, the clinician could slide each light guide gently down until it contacted the base of the sulcus. The elastomeric support allowed some flexibility of the application angle of the light guide, to follow variations among teeth. Another virtue of this second design is that it was stable against lateral tipping. The initial design contacted the tooth only at the tips of the optical guides, so that the probe had to be stabilized against tipping by placing cotton rolls between the subject's teeth.

The two subgingival probe designs were usable with all the teeth in the mouth, but were much easier to apply on anterior teeth because of improved visibility and better access for pliers or the clinician's fingers. We would try to make any new design smaller to reduce access problems in the posterior arch.

As we were developing the second subgingival probe, we recognized that our early data suggested potentially devastating corruption of pulpal signals by gingival pulses. We then chose to focus the mechanical design effort on the simpler task of making a supragingival probe, contacting the tooth about 2 $\mathrm{mm}$ above the gingival margin.

Our first approach to supragingival support of optics was to use full-quadrant molds made of various polysiloxane dental impression materials. We tested the materials used by researchers in Stockholm and Bristol, finding them not essentially different in performance from the Perfourm ${ }^{\circledR}$ soft putty and Perfourm Light used at the School of Dentistry of the University of the Pacific (UOP). A dental bur was used to create holes in the impressions that were slightly smaller than the 2-mmdiameter objects to be held therein. One hole held a meter-long glass fiber cable to supply light from an illuminator, and the other held a short stalk of single-core plastic optical fiber, to the distal end of which was glued a silicon photodiode. Electrical shielding for the photodiode was similar to that used for the subgingival clips.

Because dental impression materials required considerable preparation time for each subject, we developed a supragingival "clothespin-like" clip, with elastomeric pads that would allow us to apply fiber optic probes quickly to any subject (see Figures 5 and 6). The pads have flexible spurs that extend between adjacent teeth, which tends to center the pads on the buccal and lingual surfaces. Pad faces are hollowed to fit the bulbous tooth contours. This clip was used in the majority of experiments and worked well on premolars and molars. Vertical stabilization of the spring clip is provided by an elastomer-padded bite plate that swings into position for support when the clip is applied.

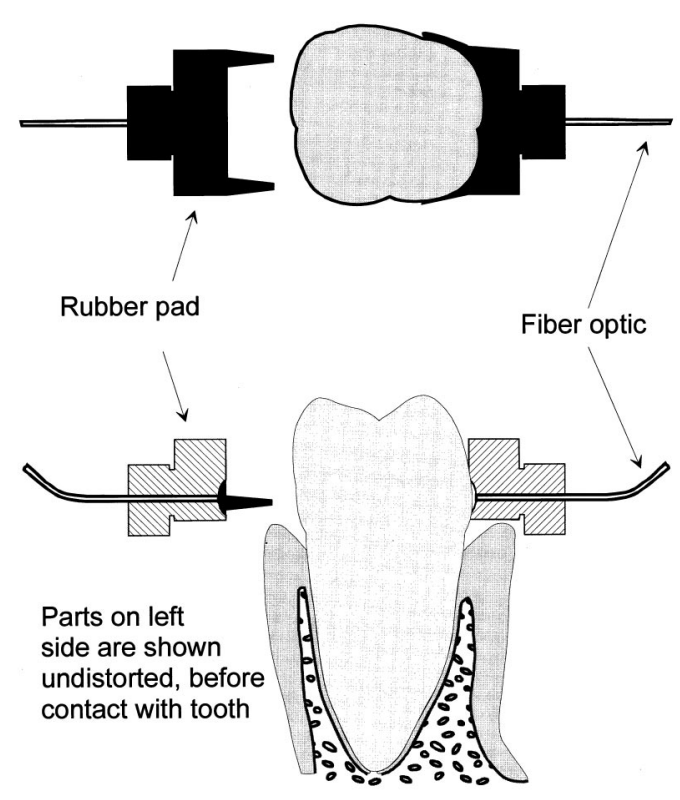

Fig. 5 Top view and vertical cross section of rubber pad abovegum clip.

The spring clip did not work well on anterior teeth (urged together by the spring force, the rubber pads would slip). For incisors and canines, we achieved adequate attachment, with modest discomfort to subjects, with the structure shown in Figure 7. This probe was a variant of the clip shown in Figures 5 and 6, made by adding metal clamps between the rubber pad and the gum. The shapes of the clamps were based on a model made by grinding the subgingival spurs off a standard universal molar rubber dam clamp. Without spurs, the clamp was sufficiently stable and reasonably comfortable for the test subject.

Almost all of the pads used in our different clip designs were molded with an oven-cured medicalgrade silicone rubber (MDX4-4210, Dow Corning Medical Products, Midland, Michigan. No longer available from this manufacturer).

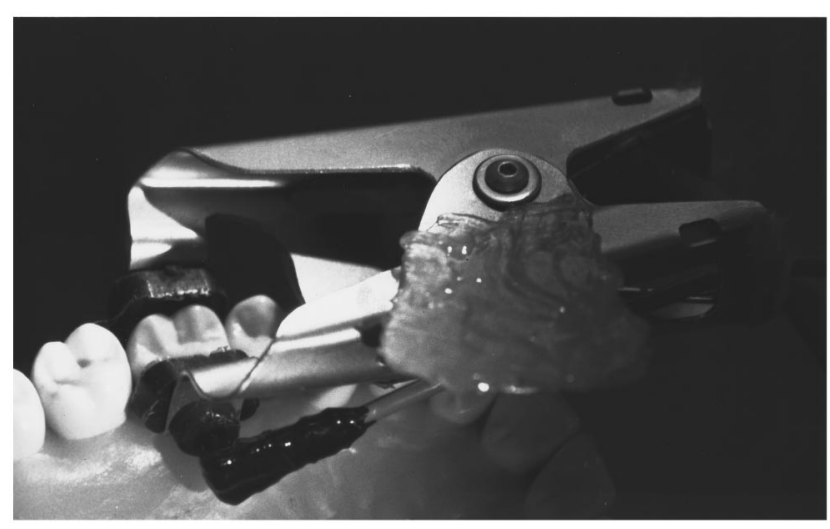

Fig. 6 Photograph of above-gum clip, with bite plate in use, on a Typodont. 

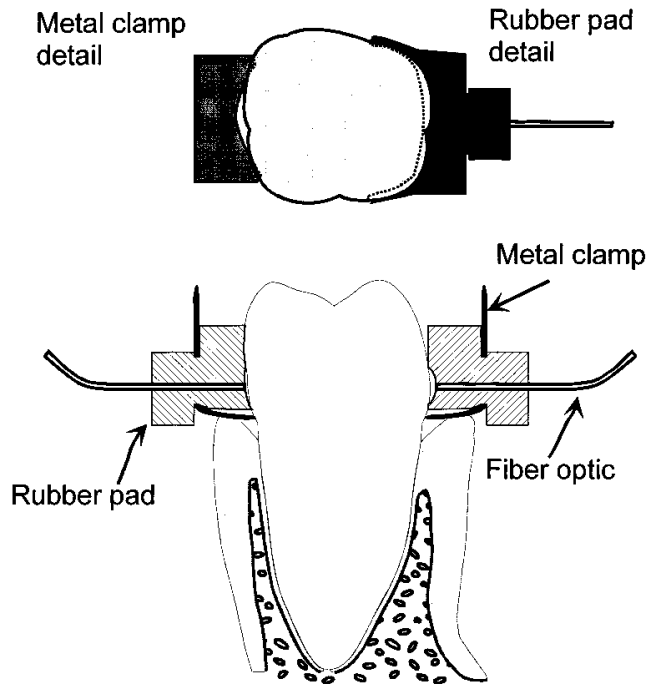

Fig. 7 Optical probe usable on front teeth.

\section{TEST SUbJECTS}

While we studied many different teeth in the course of developing equipment, only a few specific teeth were used for the critical experiments reported in this paper. Brief descriptions of those teeth appear in Table 1. All subjects gave informed consent. Work with subjects other than members of the re-

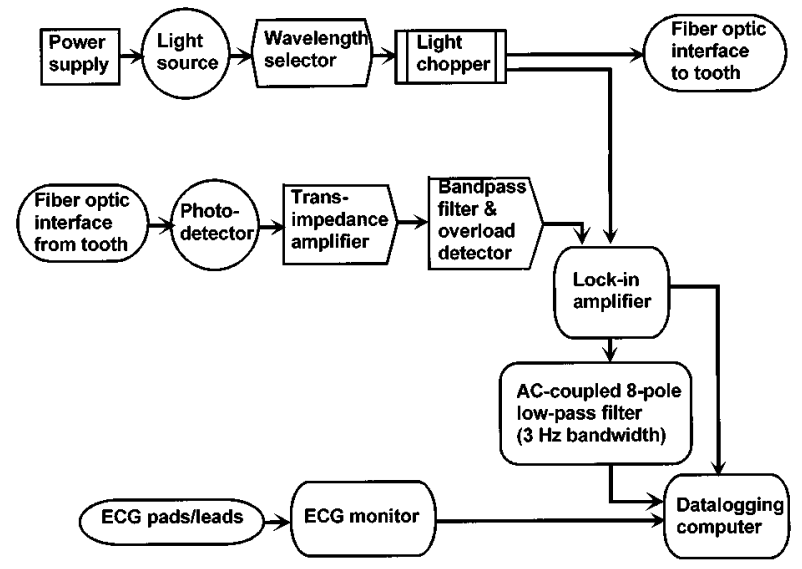

Fig. 8 Block diagram of photoplethysmograph.

search team was approved by the Institutional Review Board of the UOP Dental School.

\section{PHOTOPLETHYSMOGRAPH: EQUIPMENT AND METHODS}

Our photoplethysmograph is shown schematically in Figure 8 and is described in the following subsections.

Table 1 Profile of test subjects.

\begin{tabular}{|c|c|c|c|}
\hline Subject & Age & Tooth & Condition of tooth and gingiva \\
\hline \multirow[t]{2}{*}{ A } & 52 & 3 (upper right 1st molar) & $\begin{array}{l}\text { Vital pulp, no restorations, } 4 \text {-mm gingival } \\
\text { recession on mesio-buccal root. }\end{array}$ \\
\hline & & 5 (upper right 1 st bicuspid) & $\begin{array}{l}\text { Vital pulp, no restorations, 2-mm gingival } \\
\text { recession on buccal root. }\end{array}$ \\
\hline \multirow[t]{2}{*}{ B } & 44 & 4 (upper right 2nd bicuspid) & Vital pulp, no restorations, gingiva WNL. ${ }^{a}$ \\
\hline & & 13 (upper left 2nd bicuspid) & $\begin{array}{l}\text { Root canal, alloy restoration on occlusal } \\
\text { surface. No restorations on buccal, lingual, or } \\
\text { interproximal surfaces. Gingiva WNL. }\end{array}$ \\
\hline \multirow[t]{2}{*}{ C } & 24 & 8 (upper right central incisor) & $\begin{array}{l}\text { Necrotic pulp, incisal etched restorations, sinus } \\
\text { tract in vestibule. }\end{array}$ \\
\hline & & 9 (upper left central incisor) & Vital pulp, no restorations, gingiva WNL. \\
\hline \multirow[t]{4}{*}{ D } & 55 & 5 (upper right 1 st bicuspid) & $\begin{array}{l}\text { Necrotic, nonvital to electric pulp tester (EPT), } \\
\text { periapical radiolucency, gingiva WNL. }\end{array}$ \\
\hline & & 6 (upper right canine) & Vital pulp, resin restoration, gingiva WNL. \\
\hline & & 7 (upper right lateral incisor) & Vital pulp, resin restoration, gingiva WNL. \\
\hline & & 8 (upper right central incisor) & $\begin{array}{l}\text { Necrotic, nonvital to EPT, periapical } \\
\text { radiolucency, sinus tract present, gingiva } \\
\text { WNL. }\end{array}$ \\
\hline
\end{tabular}

Note: All subjects were male.

a $\mathrm{WNL}=$ within normal limits.

62 Journal of Biomedical Optics • January 1997 • Vol. 2 No. 1 


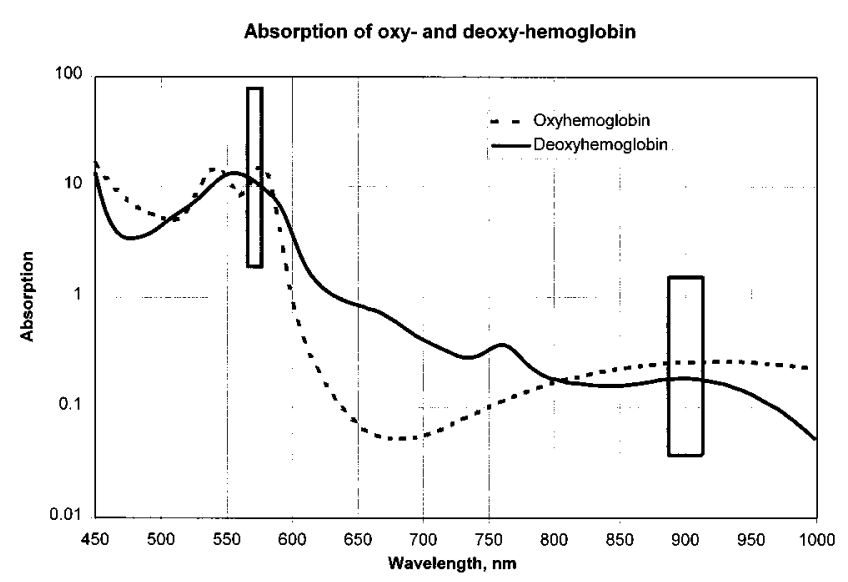

Fig. 9 Absorption spectrum of human hemoglobin and oxyhemoglobin. The rectangular windows represent the regions used for most measurements (10-nm band centered at 570 and 25-nm band centered at $900 \mathrm{~nm}$, both selected by interference filters from the white light source).

\subsection{LIGHT SOURCE}

In an initial version of our photoplethysmograph (not illustrated), we incorporated a spectrometer between a xenon arc lamp and the illumination fiber bundle, so that wavelength could be varied continuously. Using the spectrometer, we determined which wavelengths displayed the greatest pulsatile modulation when we sent light through teeth. We found the best performance at 570 and $900 \mathrm{~nm}$, and thereafter did all our work at those wavelengths. Figure 9 shows that the empirical choice of best wavelength is well explained by absorption peaks in the two forms of hemoglobin which are the principal optical absorbers in human blood. ${ }^{23}$

Throughout our study, we made measurements at two wavelengths rather than one, simply in hope that we would learn something interesting by comparing results at the two wavelengths. We found little extra information at $900 \mathrm{~nm}$. There was a larger percentage modulation in the green, explainable by the higher absorption there, but much better light transmission in the infrared. We could sometimes obtain $900-\mathrm{nm}$ pulses when the $570-\mathrm{nm}$ probe was too weak to be useful.

To reduce noise, we replaced the xenon arc lamp with a tungsten-halogen lamp (Osram HLX-64625) selected for high luminous efficiency and high radiance. The lamp was driven by a quiet dc power supply (Hewlett-Packard 6642 dc, operating in voltage-regulated mode). A limitation of the incandescent source was its weak output at short wavelengths; Figure 9 suggests that we might otherwise have seen excellent performance at 540 and $<450$ nm.

Light was delivered to the tooth by a glass fiber bundle having an end diameter of $1.5 \mathrm{~mm}$. With lamp voltage at the rated $12.0 \mathrm{Vdc}$, optical power delivered to the input end of this bundle was 2.1 $\mathrm{mW}$ when a $570 \times 10$-nm full-width half-maximum (FWHM) filter was in use, and $9.3 \mathrm{~mW}$ with a 900 $\times 25$-nm FWHM filter.

\subsection{MODULATION AND DETECTION}

Table 2 lists the equipment used to achieve low noise modulation and detection of light. The most difficult development problem, finally solved by using the tuning fork chopper and DSP synchronous detector, was achieving sufficient phase stability. In a commercial apparatus no longer needing wavelength flexibility, the use of light-emitting diodes would make phase stability much easier to achieve.

The preamplifier was located in a small electrically shielded box clipped to the subject's shirt so that the lead length from the preamp to the detector in the patient's mouth could be held to $30 \mathrm{~cm}$, thus reducing cable capacitance and electromagnetic noise pickup.

Table 2 Modulation and detection apparatus.

\begin{tabular}{|c|c|c|}
\hline Component & Manufacturer and model & Key parameters \\
\hline Light chopper & $\begin{array}{l}\text { Model CH-10-90D } 159 \text { tuning fork } \\
\text { chopper, with AGC-110 driver. } \\
\text { Electro-Optical Products Corp., P.O. Box 650441, } \\
\text { Fresh Meadows, NY } 11365\end{array}$ & $\begin{array}{l}159 \mathrm{~Hz} \text {, stable to } 0.005 \% \text {, } \\
\text { amplitude stability }<0.01 \%\end{array}$ \\
\hline $\begin{array}{l}\text { Preamplifier (modified } \\
\text { commercial oximeter } \\
\text { preamp) }\end{array}$ & Nellcor Puritan Bennett, Inc. & $\begin{array}{l}\text { Differential transimpedance } \\
\text { input stage. Noise referred to } \\
\text { amplifier input: } \\
\text { at maximum gain } 35 \mathrm{fA} \mathrm{rms} \\
\text { at minimum gain } 90 \mathrm{fA} \mathrm{rms}\end{array}$ \\
\hline Filter & Custom made & $159 \pm 3 \mathrm{~Hz}$ passband \\
\hline Synchronous detector & $\begin{array}{l}\text { Model SR 830. Stanford Research } \\
\text { Systems, 1290-D Reamwood Ave., } \\
\text { Sunnyvale, CA } 94089\end{array}$ & Digital signal processor (DSP) \\
\hline
\end{tabular}




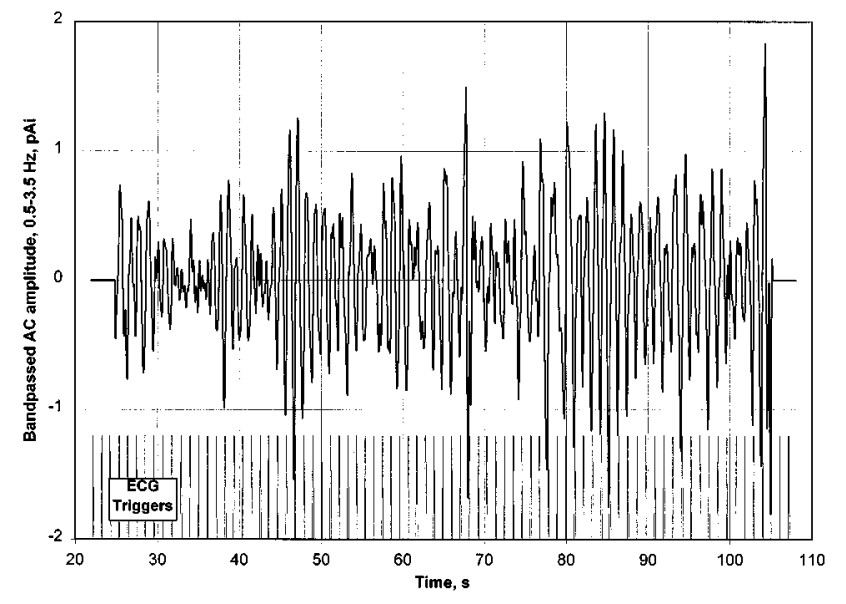

Fig. 10 Representative plot of small pulse signals from a tooth (modulation $0.007 \%$ rms). Note synchrony of pulses with ECG triggers at bottom.

With a maximum signal level before overload of 5 $\mathrm{nA} \mathrm{dc}$, the noise level of $90 \mathrm{fA}$ (which is at the fundamental physical limit set by shot noise) corresponds to a detection threshold of $0.002 \% \mathrm{rms}$, at a signal-to-noise ratio of 1 . To lend realism to this small number, Figure 10 shows a typical signal with $0.007 \%$ rms modulation before signal averaging was applied. The ecg triggers at the bottom of the display provide a reference at the subject's pulse rate. The very low noise threshold was important in observing the weak remaining pulsatile signals when opaque material was placed between the tooth and gingiva.

\subsection{ELECTROCARDIOGRAPH}

We used a conventional 3-lead electrocardiograph (ECG) (Propaq Model 106EL, Protocol Systems, Beaverton, Oregon) with electrodes on the right and left chest and lower left abdomen, in lead 2 configuration, to obtain trigger signals coincident with the subject's QRS complex. These triggers were recorded by the multichannel data logging system to support later ECG-synchronous signal averaging in software. Averaging 100 pulses gave the expected tenfold improvement in signal-tonoise ratio.

\subsection{DISTINGUISHING PULP SIGNAL FROM SUPPORTING TISSUE SIGNAL}

Optical probes to assess pulpal vitality must be shown to respond much more strongly to the circulation of the dental pulp than to circulation in the gingiva, periodontal membrane, or adjacent bone. Our experiments focused primarily on the gingiva, which represents a large volume of well-perfused tissue, very close to the optical probe on the tooth. In our test subjects, so much signal originated in the gingiva that the periodontal membrane and bone could be discounted by comparison.

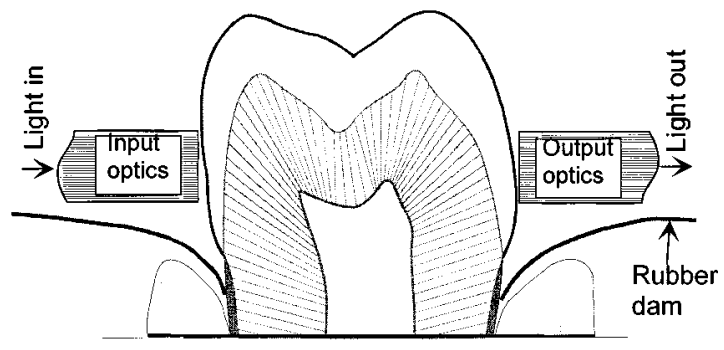

Fig. 11 Using rubber dam to assist in optical isolation of the gingiva.

We developed two approaches to distinguishing pulpal from gingival signals. First, by placing opaque material in the gingival sulcus, we could suppress that portion of the signal which resulted from direct optical communication between the tooth and the free gingiva. Second, by injecting Lidocaine with a vasoconstrictor at several points near the gingival margin, we could blanch the gingiva.

To blanch the gingiva, we injected $2 \%$ Lidocaine $\mathrm{HCl}$ with 1:50,000 epinephrine at six points close to the gingival margin (at the four line angles and directly buccal and lingual). The injected volume was just enough to cause visible blanching, typically about $0.15 \mathrm{ml}$ for all six points together. The facts that this dosage was only a tenth of the typical dose used for pulpal anesthesia, and the injection sites were remote from the apex of the tooth, reduced the likelihood that the injection would affect pulpal circulation.

Gazelius et al. ${ }^{19}$ described the use of rubber dam material to block light to tissues near the tooth. Amess et al. ${ }^{24}$ changed from the standard translucent green dam to custom-cut black rubber material, led by their observation ${ }^{25}$ that this reduced single-pass transmission of both red and nearinfrared laser beams from $50 \%$ to less than their 1\% threshold of detection. We used the same black dam material employed by the Bristol group (Grade $\mathrm{S}$ black latex rubber sheeting, 0.010-in. thick, 6 in. square; Four D Rubber Co., Ltd., Heanor, Derbyshire, England).

It appeared to us that the primary function served by the dental dam was to block partially the optical communication between the tooth and the immediately adjacent gingiva (see Figure 11). We found that the tendency of the elastic rubber material to pull itself into a compact shape made it almost impossible to induce the edge of the rubber material to conform to the bottom of the gingival sulcus, so that this method could reduce but not eliminate optical communication with the free gingiva.

We tried using low-viscosity dental impression material such as Perfourm Light to fill the gingival sulcus. We concluded that such material could probably be modified to serve the purpose by adding light-blocking fillers. (We recently learned that such modification has been tried by the Bristol 


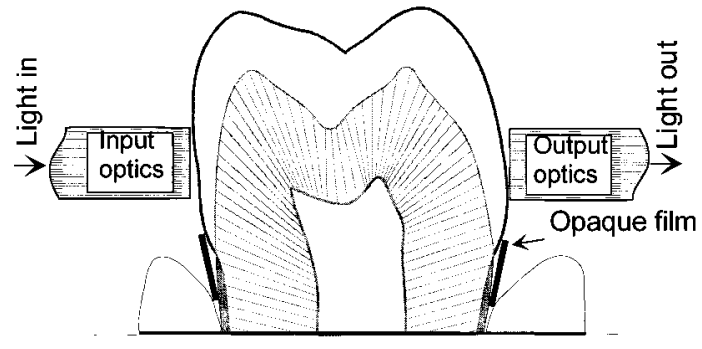

Fig. 12 Plastic film in the gingival sulcus improves optical isolation of free gingiva.

group, with partial success. ${ }^{26}$ ) We placed material in the sulcus with the same pneumatic syringe that we used to place black, light-blocking fluids in the sulcus (see later discussion). The dental impression materials were too fragile to make reusable sulcusfilling impressions and, in a one-time application, harder to use and remove than were the opaque fluids we developed.

Edwall et al. ${ }^{27}$ used black plastic film to isolate the gingiva optically from the tooth for experiments in rats and cats. In our experiments with human subjects, $75-\mu \mathrm{m}$ black polyethylene film was the most effective light-blocking material we found (Figure 12). We cut 3-mm-wide strips of this material, about $20 \mathrm{~cm}$ long, and guided them around the tooth and into the base of the sulcus, using cotton pliers and floss threaders. The plastic strips could be prevented from dislodging by a variety of methods. We had early success in using balsa wedges between the teeth, but finally evolved a method of wrapping adjacent teeth through the contacts, forming loops to isolate the experimental tooth. Placing the black strips in the sulcus could take as much as 15 min per tooth, which disqualifies this as a routine clinical procedure, but this method could be adapted to differently shaped sulci (sometimes by cutting and inserting several different strips around a single tooth). It was a reasonably reliable method of ensuring good light attenuation. A further advantage of these plastic strips over the dental dam was that the strips did not interfere with placement close to the gingival crest of the rubber tooth-clamping pads that supported our fiber optics. The effectiveness of black plastic film was quite variable from tooth to tooth, and even to some extent from day to day on the same tooth. We attribute this difference in part to the difficulty of shaping the plastic film to follow exactly the bottom of the sulcus, a difficulty that an appropriate fluid would presumably overcome.

We began development of a viscous black, lightblocking fluid (Figure 13), which could rapidly be placed into the gingival sulcus with a pneumatic syringe. We produced fluids that would stay in place reliably, though the subject could easily rinse them out with a few sips of water. Key constituents of a mixture were a finely divided black powder for opacity, a thickener to provide enough body to ex-

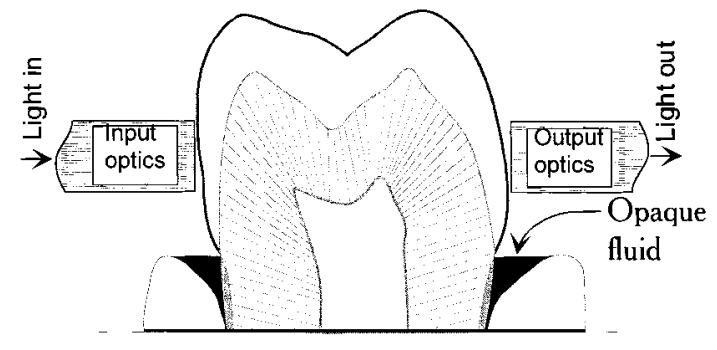

Fig. 13 Viscous opaque fluid in the gingival sulcus may provide the best optical isolation.

pand the sulcus somewhat (this improved attenuation), and a sticky material to promote retention in the sulcus. Our best mixture consisted of $15 \%$ black iron oxide (BL940; Whittaker, Clark, and Daniels, Laguna Hills, California), 5\% methyl cellulose (ME137; Spectrum Chemical Manufacturing Corp., Gardena, California), and 5\% xanthan gum (XA105; Spectrum Chemical Manufacturing Corp.) in water. Attainable optical attenuation steadily improved and there were prospects of further improvement, but as shown in Table 3, we needed great improvement to match the best performance of black plastic film on the same teeth. The most promising direction appeared to be to use finely divided carbon black as the pigment, assuming that the difficulty of attaining complete dispersion could be overcome.

\subsection{RECORDING AND PROCESSING DATA}

The lamp drive voltage was always set so that the brightest anticipated condition would approach the maximum permitted preamplifier signal (lamp voltage was typically about $2 \mathrm{~V}$ when the 900-nm filter was in use, and close to the full-rated $12 \mathrm{~V}$ with the 570-nm filter).

Data recordings were at least $60 \mathrm{~s}$ long (typically 70 to $100 \mathrm{~s}$ ). Data were collected at approximately 18 samples/second (using the DOS clock of an IBM-compatible personal computer). Software postprocessing derived several signal strength measures for each file, including the measures reported in this paper-average dc level of light transmitted through the tooth, expressed in picoamperes referred to amplifier input (pAi), and root-meansquare (rms) percent pulsatile modulation. The modulation percentage was computed for an aver-

Table 3 Comparison of best black fluid results with best black plastic results.

\begin{tabular}{lcc}
\hline Material & $\begin{array}{c}570-\mathrm{nm} \\
\text { attenuation } \\
\text { factor }\end{array}$ & $\begin{array}{c}900-\mathrm{nm} \\
\text { attenuation } \\
\text { factor }\end{array}$ \\
\hline Black fluid & 7.8 & 10.1 \\
Black plastic & 300 & 250 \\
\hline
\end{tabular}

Note: "Attenuation factor" is the ratio of detected light intensity without black material, to intensity with material in place. 

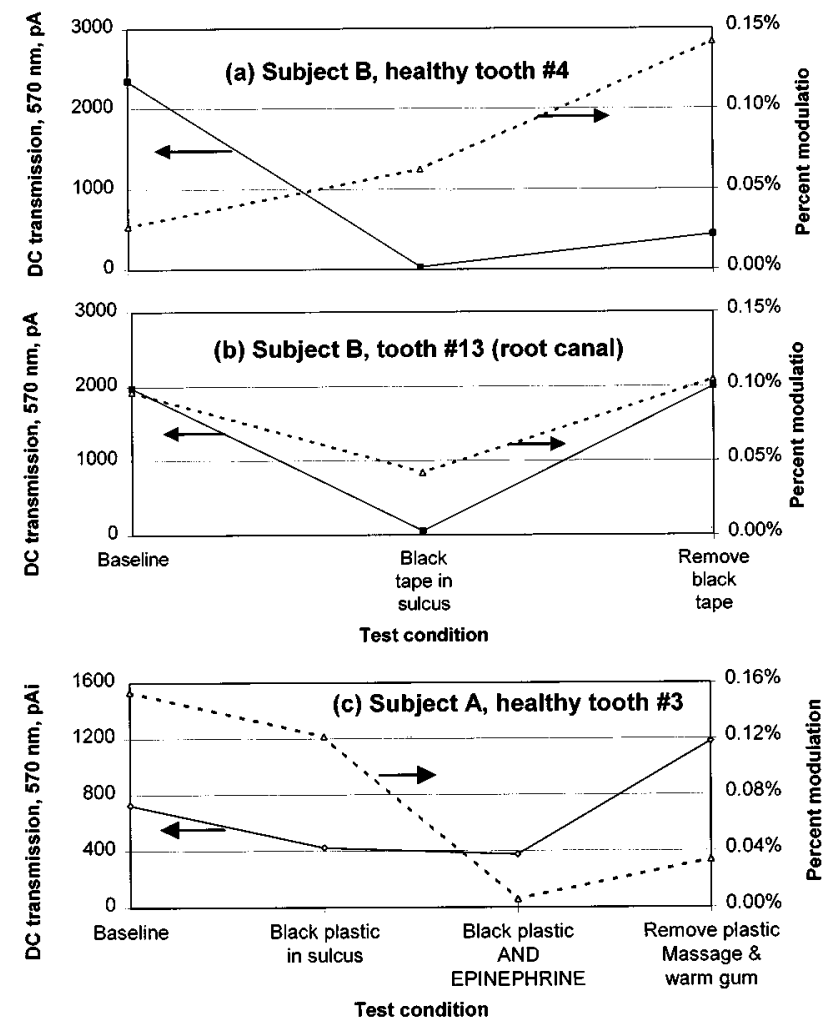

Fig. 14 Effects of black plastic in the gingival sulcus and of epinephrine injection. Dashed lines represent percent modulation, and refer to right-hand scale. Solid lines represent dc light transmission, and refer to left-hand scale.

age pulse, obtained by averaging the signals in all of the intervals between ECG triggers.

Experiments typically included a noise reference run in which the light source was on, but the sensor was placed under a cover near the subject, with light passing directly from the emitter to the detector, while we recorded the detected light and the subject's ECG triggers. Once our equipment matured, the signal-averaged noise thresholds were typically in the range of 7 to $12 \mathrm{fA}$, referred to amplifier input, which corresponds to a modulation at full-scale signal ( $5 \mathrm{nA} \mathrm{dc}$ ) of about $2 \times 10^{-4} \% \mathrm{rms}$.

\section{PHOTOPLETHySMOgRAPH RESUltS}

Figure 14, excerpted from a particular day's experiments, illustrates the key observations which led us to question the value of dental photoplethysmography in middle-aged subjects. Results similar to those in Figures 14(a) and 14(b) were also obtained on that day with subject A. These experiments were repeated, with similar results, on other days.

The first two sequences [Figures 14(a) and 14(b)] show the effect on 570-nm light transmission of placing black plastic strips in the gingival sulci of two teeth of subject $B$, one tooth being healthy and the contralateral tooth having had a root canal. When the plastic was inserted, the dc light level dropped precipitously, while pulse shape and per- centage modulation were sufficiently similar on the vital and nonvital teeth to make it impossible to distinguish them by these means. The similar modulation percentages seen on the two teeth implied that much of the remaining signal after insertion of the plastic was still coming from tissues adjacent to the teeth-i.e., from bone, from the periodontal membrane, or from the gingiva (despite the blocking of the free gingiva, it would still have been possible for light to find its way into gingival tissue by passing below the sulcus).

Figures 14(a) and 14(b) show that when the black plastic was removed, pulsatile modulation increased to a level exceeding the baseline, perhaps due to hyperemia induced by disturbance of the gingiva. Figure 14(c) shows a sequence in which a vasoconstrictor was injected near the gingival margin of one vital tooth of subject A after placement of black plastic. For this subject, on this day, placing the plastic caused only a modest drop in dc attenuation. The injection caused visible blanching of the gum. The dc transmission was again little affected. The modulation percentage, however, dropped from 0.128 to $0.006 \%$ at $570 \mathrm{~nm}$ and from 0.033 to $0.004 \%$ at $900 \mathrm{~nm}$. The remaining modulation levels after epinephrine injection were low enough to be indistinguishable from random noise (low dc levels caused the noise threshold in this test to be relatively high). This result supports the belief that the pulsatile signal seen after placement of the black plastic strips was caused by gingival circulation.

Subject $C$ had one necrotic and one healthy upper central incisor. We found it impractical to achieve significant reduction of detected light intensity by positioning opaque plastic in the gingival sulci of these teeth. In the absence of such blocking, signals from the vital and necrotic teeth were virtually indistinguishable. On subject D, we were able to compare signals from vital tooth 7 with nonvital tooth 8 , in the absence of effective light blocking between tooth and gingiva. Percentage modulations were similar on the two teeth. Also in subject D, on nonvital tooth 5, introducing black plastic strips between the tooth and gingiva reduced light transmission through the tooth to $1.6 \%$ at $570 \mathrm{~nm}$ and $0.3 \%$ at $900 \mathrm{~nm}$, compared with the values before insertion of plastic.

We believe that, at least in these subjects, much of the light detected by a dental photoplethysmograph has passed through the gingiva, that most of the pulsatile modulation comes from the gingiva, and that even when optical communication with the gingiva is reduced, most of the remaining pulsatile modulation comes from tissues other than the dental pulp.

\section{LASER DOPPLER FLOWMETER: EQUIPMENT AND METHODS}

Having decided that the photoplethysmograph was unlikely to become the generally useful instrument 
Table 4 LDF tests on vital teeth of two subjects.

\begin{tabular}{|c|c|c|c|c|c|}
\hline Condition & Tooth & $\begin{array}{c}\text { Total } \\
\text { backscatter }\end{array}$ & $\begin{array}{c}D C \\
\text { perfusion }\end{array}$ & AC perfusion & $A C / D C$ \\
\hline Baseline & A \#3 & 3 & 1.44 & 0.112 & $7.8 \%$ \\
\hline Black plastic in sulcus & & 3 & 0.621 & 0.0438 & $7.1 \%$ \\
\hline Black plastic and epinephrine & & 2.5 & 0.257 & $<0.0182$ & $<7.1 \%$ \\
\hline Baseline & $\begin{array}{c}\text { A \#5 } \\
\text { (1 st day) }\end{array}$ & 2.0 & 0.835 & Lost in noise & NA \\
\hline Black plastic in sulcus & & 1.8 & 0.632 & Lost in noise & NA \\
\hline Black plastic and epinephrine & & 2.0 & 0.336 & Lost in noise & NA \\
\hline Baseline & $\begin{array}{c}\text { A \#5 } \\
\text { (2nd day) }\end{array}$ & $1.6-1.9$ & 2.56 & 0.374 & $14.6 \%$ \\
\hline Black plastic in sulcus & & 1.8 & 1.85 & 0.309 & $16.7 \%$ \\
\hline Black plastic and epinephrine & & 2.0 & 0.189 & $<0.0374$ & $<19.8 \%$ \\
\hline Baseline & B \#4 & 4 & $1.0-3.0$ & $<0.25$ & $9 \%(?)$ \\
\hline Black plastic in sulcus & & 4 & Near-zero & ? & $?$ \\
\hline
\end{tabular}

we sought, we experimented with a commercial LDF (Periflux 4001, with Perisoft software version 5.09. Perimed AB, Järfälla, Sweden). It seemed possible that the LDF would work where the photoplethysmograph had not because the LDF has an inherent advantage-it does not depend for its sensitivity upon fluctuations in the concentration of blood in tissue. If blood is moving, even in a channel of unchanging diameter, the LDF should be able to detect it, while the photoplethysmograph's possible ability to detect it depends on second-order phenomena, as discussed earlier.

We determined the "dc" or average value of perfusion, measured in perfusion units, and the "ac" value of this parameter, which is the cardiac-rate pulsatile modulation. Perfusion units relate the observed signal to the signal produced by Brownian motion of standard latex microspheres in a known vehicle. Most LDF experts believe that there is no simple quantitative relationship between perfusion units and common measures of blood flow (e.g., $\mathrm{ml} / \mathrm{cm}^{3} \times \mathrm{s}$ ). Such a relationship is especially unlikely in the intact tooth, since much of the light returning to the instrument has been backscattered by the bloodless hard tissue surrounding the pulp. Still, we hoped that meaningful comparisons could be made between contralateral teeth having different pulp conditions. The LDF was zeroed and calibrated with the tools provided for this purpose by the LDF manufacturer-a white plastic block for the zero-motion reference, and a suspension of latex spheres for calibration.

To measure pulsatile modulation strength, we Fourier analyzed files logged by the Perisoft soft- ware. (We used the DADISP software package provided by DSP Development Corp., Cambridge, Massachusetts.) The conventional analytic sequence we used included clipping of motion-induced spikes and multiplying by a Hamming window, followed by Fourier analysis.

The dc perfusion was taken as the value of the zero-frequency term in the Fourier analysis. The ac perfusion was calculated as the rss (root sum of squares) of the signals at frequencies within the cardiac-rate peak. When, as a result of actions taken to attenuate signal from the gingiva, the pulse became so small that no peak was observable above the noise in the Fourier plot, the ac modulation was reported as $<x x$, where $x x$ is the rss of the same group of frequencies that were summed in the unattenuated signal.

\section{LASER DOPPLER FLOWMETER RESULTS}

Key data from the LDF experiments are shown in Table 4. First, we observed the effect on signal strength of placing opaque material between tooth and gingiva. On both test subjects, LDF signals from known-vital teeth were attenuated significantly by inserting black plastic or viscous black fluid in the gingival sulcus. This showed that much of the Doppler-shifted light had spent part of its trajectory in the free gingiva. This experiment did not yet prove that the dominant signal originated in the gingiva. On subject A, we also saw that pulsatile modulation was attenuated in about the same proportion as the dc signal (i.e., the percent modulation was similar before and after inserting the 
opaque film), so that the ac signal provided no special promise of helping to distinguish between pulpal and gingival signals.

This first type of experiment left open a possibility that the origin of the LDF signals is at least partially in the pulp. It remained conceivable, in fact, that all of the signal originated in the pulp, and that the light-blocking material caused attenuation simply by blocking that signal during its brief excursion into the gingiva. If this were true, we might still have hoped to test pulp condition with the LDF.

On two teeth of subject A, we conducted a second type of experiment, which proved decisive. We injected the gingiva, using Lidocaine with epinephrine 1:50,000, visibly blanching the gingiva. Injection greatly reduced the LDF signals that remained after the gingiva was blocked with black material. This was persuasive evidence that, even with the gingival sulcus blocked, much of the remaining signal originated in the gingiva. The LDF signal detected before injection must have been carried by light that diffused out of the tooth into the gingiva below the line of gingival attachment to the tooth (hence below the opaque material in the sulcus), then diffused back into the tooth so that it could reach the detector.

Light levels ("total backscatter") detected by the LDF were reduced only slightly by black plastic in the gingival sulcus, which is not surprising because we used the instrument in the conventional "reflection" mode, in which illumination and detection fibers are very close to one another, so that most of the detected light has backscattered from nearby hard tooth material. Had we used the LDF in transmission mode, ${ }^{28}$ we would have expected the same dramatic reduction in light intensity that we saw with the photoplethysmograph.

\section{DISCUSSION}

When inserting black material in the gingival sulcus causes a great reduction in detected light, it creates a strong suspicion, but not a certainty, that most observed pulsatile modulation comes from the gingiva. Ray 1 in Figure 15 shows that reduced light intensity or modulation percentage need not mean either that most modulation comes from the gingiva or that light rays passing from emitter to detector spend most of their time in the gingiva. The slightest excursion of a ray into the gingiva, along the ray's jagged path from emitter to detector, permits it to be absorbed by the blocking material. The same caution applies to the inverse experiment reported by Amess et al. (Ref. 28, oral presentation). By filling the pulp cavity of an extracted tooth with black paint, they suppressed most LDF light transmitted through the tooth. This result implies only that most light rays spend at least a small part of their trajectory in the pulp space. Combining our results with those of Amess

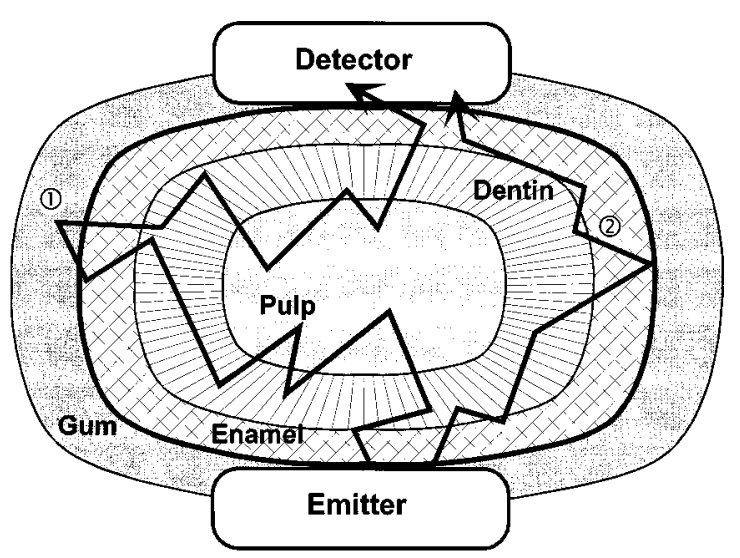

Fig. $15100 \times$ light reduction does not mean that light spends $99 \%$ of its path in the gingiva. Ray 1 travels mostly in the body of the tooth, but opaque material in gingival sulcus will absorb it. Ray 2 reflects internally from tooth boundary. Opaque material in sulcus may absorb it.

et al., we suggest that most rays traversing the tooth probably touch both the gingiva and the pulp somewhere in their trajectory, and that additional information is always needed to establish which of these soft tissues dominates in modulating the light.

Ray 2 in Figure 15 suggests a subtler way in which the black-plastic experiments could have been misleading. If many rays were internally reflected from tooth surfaces, black material contacting the tooth surface might act like "optical blotting paper," soaking up these rays and contributing to the observed attenuation, even though the absorbed rays never would have entered the gingiva in the absence of the black material. There is sufficient mismatch in refractive indices between hard tooth materials and the crevicular fluid or gingival tissue with which the tooth is normally in contact so that some internal reflection is likely. The epinephrineinjection experiments showed that in our case there was enough light reaching the gum to dominate any optical modulation we detected.

The straightforward interpretation of the experiments in which we used epinephrine to blanch the gingiva is that the observed signal reduction implied that most signals originated in the gingiva. We must consider the more convoluted interpretation that the reduction in signal was in fact caused by an unintended reduction in pulpal blood flow. Giddon $^{29}$ used a photoplethysmograph to show that cold pressor stimulation of a human subject, as well as the subject's anticipation of this stimulation, could cause simultaneous moderate vasoconstriction in gingiva and finger. One can imagine that such a universal reaction could include the dental pulp. We were irritating the gingiva by inserting black material in the gingival sulcus and by inserting needles in the gingiva itself. Could these irritations somehow induce vasoconstriction in the pulp? A recent study in cats $^{30}$ showed the opposite 
effect-irritation of the gingiva caused an increase in pulpal blood flow. Vongsavan et al. ${ }^{31}$ found that electrical stimulation of the human tooth in vivo produced no detectable effect on pulpal circulation. Pitt Ford and colleagues ${ }^{32-34}$ used LDF to measure pulpal circulation when influenced by anesthetic injections with and without epinephrine, purposely injecting at sites which do affect the pulpal circulation. The observed reductions in pulpal circulation were on the order of $50 \%$, which is very different from the profound suppression of pulsation in our experiments. Furthermore, the apparent pulpal effects reported by these investigators may have been in part influenced by changes in gingival circulation. In view of the limited evidence in the literature, we think it unlikely that the pulse suppression we observed was a pulpal effect.

The gingiva is not the only pulsatile tissue near the tooth. Some LDF studies address blood flow in oral bones (cf. Ref. 35). Packman, Shoher, and Stein $^{36}$ sensed pulses in the periodontal ligament with a photoplethysmograph. Because we could suppress almost all modulation seen by a photoplethysmograph by blanching the gingiva, we believe that in our experiments gingival signals were dominant.

Matthews and Vongsavan ${ }^{37}$ found in pigs that $10 \%$ of the signal detected by an LDF on the tooth probably comes from the gingiva. By cutting the pulp, they could eliminate $90 \%$ of the signal, suggesting that this fraction of the signal originated in the pulp, while $10 \%$ originated elsewhere. Later experiments in which an LDF was used before and after pulp extirpation have persuaded this group that in humans, unlike pigs, most of the detectable signal probably originates in tissues other than the pulp. ${ }^{38}$ Our results support their conclusion-we can say at least that gingival signals dominate in middle-aged adult humans.

In view of the influence of gingival circulation upon optical observations of the tooth, some results in the literature may have been affected by circulation in the gingivae when the authors believed that they were observing the dental pulp. We cannot attempt a comprehensive review of this extensive literature, but offer a few examples of the sort of critique that might be applied.

- All published reports we have seen of photoplethysmography or pulse oximetry as vitality probes for human teeth must be reconsidered, because none of these published articles provides persuasive evidence that the signals came from the pulp rather than the gingiva.

- Ramsay et al. ${ }^{39}$ found LDF signals from adult human teeth to be stronger near the gingival crest than near the incisal edge of the tooth. While their results might derive simply from the fact that more of the pulp is located at or near the height of the gingival crest than near the incisal edge, a possible reinterpretation is that the always-dominant gingival circulation is seen more clearly as the probe approaches the gingiva.

- Ingólfsson et al. ${ }^{40}$ showed that signal strength increased with larger spacing between the light-emitting and light-detecting probes of the LDF. This is reasonable, in view of our knowledge from computer modeling studies (cf. Ref. 41) that the mean depth in tissue traversed by surviving photons in a reflectance optical sensor increases with increasing spacing between sensors. There is an important difference in optical properties between teeth and the soft tissues in which the LDF is most often applied, which enhances this increase in penetration depth. In the presence of the strong optical absorption typical of soft tissue, any deeply penetrating photon is likely to be absorbed before it finds its way back to the photodetector on the surface. The low absorption characteristic of enamel and dentin allows deeply penetrating photons to survive to be detected. Greater penetration depth increases the chance that a surviving photon has contacted pulsatile tissue, either gingiva or pulp. So, as Ingólfsson and co-workers increased the separation of their emitter and detector, light penetrated more deeply into the tooth (and perhaps into the adjacent tissues), became more likely to touch perfused tissue before it was detected, and therefore exhibited greater modulation.

- Amess et al. ${ }^{28}$ carried the increase of emitterdetector spacing to an extreme by placing the LDF receiver on the far side of the tooth from the transmitter. Since the shortest path from emitter to detector now passed directly through the pulp, this configuration increased the likelihood that rays would contact perfused tissue. This arrangement could not, however, guarantee that any signal detected was from the pulp. Figures 1 and 15 suggest that much light may have bounced around the pulp, with a substantial likelihood of contacting the gingiva in its travels. Both our results and those of the Bristol group suggest that gingival circulation did in fact dominate their measurements.

- A guideline for the use of optical probes that seems useful, in view of our own experiments, is that any optical probe intended to sense pulpal circulation should be placed on the tooth as far from the gingiva as is practical, given the need to obtain a detectable signal. This will maximize the chance that any signal comes from pulp rather than from gingiva. Many articles describe placement of the probe with its centerline about $2 \mathrm{~mm}$ from the gingiva. This position would, in many patients, put the probe closer to the gingiva than to the 
pulp. A stronger LDF signal is probably observed here than at a location further from the gingiva, but investigators who use this instrument position should seek supporting evidence that the pulpal signal is dominant in their results.

- Heithersay et al. ${ }^{42}$ reported severe attenuation of LDF signals by discolored teeth. In their judgment, LDF is an unreliable test of pulp vitality in the presence of such discoloration. We would add that when blood breakdown products reduce optical access to the pulp, this increases the likelihood that any LDF signals which are seen have arisen in the gingiva.

- McDonald and Pitt Ford ${ }^{43}$ report studies of pulpal blood flow during application of orthodontic forces. Their results could, in principle, be reinterpreted as representing changes in circulation in the soft tissue and bone nearest the LDF probe. Hertrich and $\mathrm{Raab}^{44}$ have shown that periodontal circulation, as measured by LDF, is indeed affected by orthodontic forces.

- There has been some use of the LDF for basic investigations in pulp biology. Perimed ${ }^{45}$ offers an entry point to the literature. Any such study which uses an LDF probe on the surface of the human tooth, rather than implanted close to the pulp, should be examined for the possibility that gingival circulation affected the observations. We acknowledge the frustrating conflict between possible signal contamination by the gingiva if the probe is on the tooth surface and possible physiological interference with the pulp ${ }^{25}$ if the probe is implanted.

- In several animal species-(dog), ${ }^{3,6}$ cat and rat,$~^{27}$ and pig $^{46}$-it has been shown by disrupting the pulpal circulation that the LDF was in fact observing pulpal circulation. The cited authors have argued, by cutting the pulp and observing that signals disappeared, that LDF signals originate in the pulp. Figure 16 shows the (correct) way in which one such experiment was done by Gazelius. ${ }^{47}$ Had the cut been made on the side toward the LDF probe, the shortest path between tooth and gingiva would have been interrupted, reducing any signal coming to the LDF probe from the gingiva! If a saw blade rather than a drill had been used on the side of the tooth remote from the probe, then any communication to the gingiva on that side would have been interrupted. By using a drill on the side remote from the optical probe, Gazelius maximized the extent to which the experiment affected only the pulpal circulation. A method even more immune to artifact is to cut the pulp near the apex of the tooth, ${ }^{46}$ so that any optical dis-

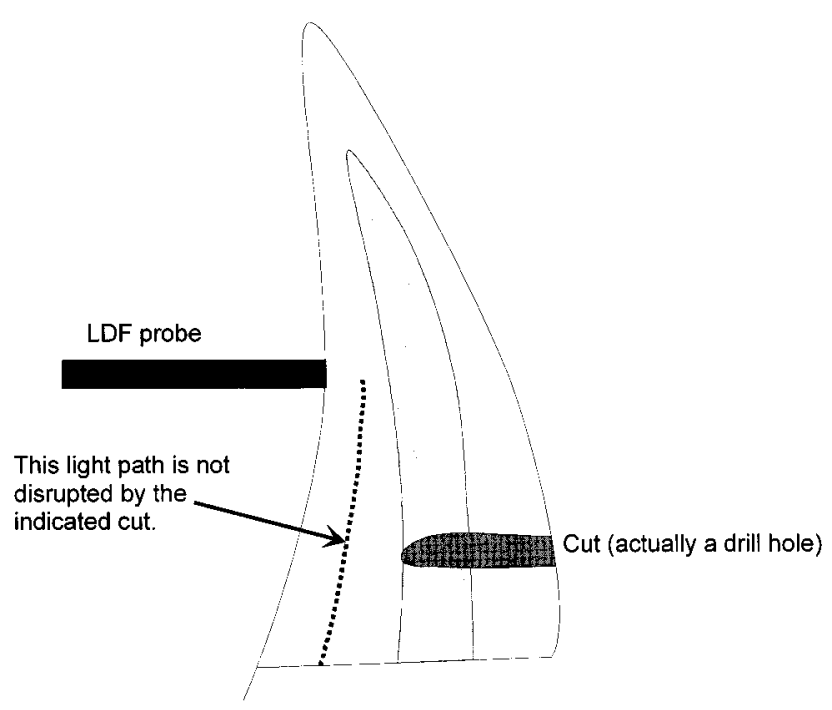

Fig. 16 Pulp-cutting experiments can falsely imply that signals originate in the pulp (see text for discussion).

turbance induced by removal of mineralized tooth material is as far as possible from the LDF probe.

We observed interesting features in LDF data which might lead in time to diagnostically useful information. Like previous authors, ${ }^{48,49}$ we recorded (from subject B) a substantially smaller LDF signal from a tooth with a root canal than from the vital contralateral tooth. Our gingiva-blocking experiments led us to believe that the signal from subject $B$ originated in the gingiva, and yet here is a seeming contradiction. It is actually consistent to say that the signal originated in the gingiva, but that gutta percha causes more optical attenuation than does undisturbed pulp. Thus the gingival signal is more attenuated in passing through an endodontically treated tooth than through a healthy tooth. Raab et al. ${ }^{49}$ tried to determine whether the gingiva was responsible for the detected LDF signal, but their technique of covering the gingiva could not prevent optical communication between tooth and gingiva below the level of gingival attachment.

A related result appeared in our work with the photoplethysmograph. In subjects C and D, necrotic incisors transmitted less light than did nearby teeth with vital pulps. Thus, although percent modulation was not a useful test of vitality, perhaps simple dc transmission could suffice. This would be consistent with the suggestions of Hill ${ }^{50}$ and Rowe and Pitt Ford ${ }^{51}$ that it is possible to distinguish vital from nonvital pulps by transillumination with broadband white light. Given the complicated optical effects of restorations, we surmise that this effect could be useful only when there were no restorations either in the suspect tooth or in a contralateral tooth that was known to be vital.

There tends to be less mineralized tooth structure 
between the pulp and the tooth surface in the root than in the crown. Furthermore, as people age, pulpal circulation remains viable in roots longer than it does in crowns. These factors favor the development of subgingival probes, if only it can be demonstrated clearly that such a probe can distinguish signals arising in the pulp from those arising in the gingiva.

A confusing issue, as one attempts to understand the meaning of LDF measurements, is that probe geometry and position affect not only the strength of the frequency-shifted signal returning from perfused tissue, but also the strength of unshifted light that returns from nonperfused hard tissue. Teeth provide an unusual working environment for the LDF, because there is so much nonperfused material between the optical probe and the tissue of interest. Investigators must take pains to understand the real meaning of the various signal strength measures presented by their instruments in this unfamiliar context.

Manufacturers of LDFs for use on intact teeth should take into account the unusual signal properties to be expected because the pulpal tissue of interest is surrounded by a thick layer of scattering medium with low absorption. There is no shortage of signal in the usual sense-teeth look just as bright and shiny to the instrument as they do to our eyes, and the detector probes receive plenty of light. When the LDF measures "flux," however, it typically computes the ratio of Doppler-scattered light to all the light of laser wavelength that is detected and (because the pulp, which contributes the Doppler-shifted light, is far from the tooth surface) this normalization results in a very small signal.

While we have shown that making an instrument that is reliable on most dental patients will be difficult, there are groups of patients in whom optical techniques are already valuable, and there may well be others. We find persuasive the articles ${ }^{1,48,52}$ reporting use of the LDF to assess the status of traumatized teeth in juvenile patients. Others have begun to apply this method with some success. ${ }^{53}$

Finally, let us discuss the use of pulse oximetry and spectrophotometry as pulpal circulation sensors. Since the pulse oximeter is a two-wavelength photoplethysmograph, it must share the difficulties which we have demonstrated for a singlewavelength photoplethysmograph. The pulse oximeter faces an additional challenge-Schmitt, Webber, and Walker ${ }^{6}$ point out that the tooth is a difficult environment for pulse oximetry, because dentin and enamel permit "optical shunt," an errorinducing process in which light traverses hard tissue, from one side of the tooth to the other, never encountering the pulp cavity (see ray 2 in Fig. 1).

Simple in vitro tests ${ }^{54}$ have suggested that the optical transmission spectrum of the tooth might contain information about the health of the pulp. For example, an unambiguous indication of oxyhemoglobin in the pulpal cavity would signal the pres- ence of active circulation. The spectrophotometric approach will be difficult because of the many colors of teeth and restoration materials which exist, especially in older patients. In this varying spectral background, it is necessary to recognize some spectral feature that would disclose the health of the pulp. In older patients, any such feature will be small. Chemometric methods ${ }^{55}$ might meet this challenge of spectroscopic sensitivity, but we have less hope of a solution to the problem of separating pulpal signals and gingival signals (except in the same younger population in which the other optical methods are also promising) unless distinctive spectral features can be identified that emanate only from the pulp. In view of the experiments reported here, the simple approach of looking for oxyhemoglobin seems unpromising.

Note added in proof: We have recently seen the report by Hartmann et al., ${ }^{56}$ a laser Doppler flowmeter study, the results of which are generally consistent with ours in demonstrating contamination of pulpal LDF signals by blood flow in the periodontium. Their work was conducted on incisors, while our most dramatic results were obtained on molars and bicuspids.

\section{CONCLUSION}

We sought to develop an optical tester that would be useful in evaluating pulpal status in most of the patients who come to a dentist for evaluation. A photoplethysmograph would have been the simplest such tool, but it proved to be unpromising. We investigated briefly the laser Doppler flowmeter, finding that it had similar difficulties. In several healthy adult subjects over 40 years of age, optical signals detected from teeth were contaminated by strong signals from well-perfused gingival tissue. We did not find noninvasive means of suppressing these signals sufficiently to permit assessment of pulpal status.

Any experiment based on optical probing of human dental pulp circulation by a probe on the surface of the tooth should be supported by evidence that the probe is responding primarily to pulpal circulation rather than the circulation of other tissues around the tooth. Two methods that are helpful in recognizing the effects of gingival circulation are insertion of opaque material in the gingival sulcus and injection of a vasoconstricting drug near the gingival margin. Based on studies with these methods, we believe that neither photoplethysmography nor simple laser Doppler flowmetry will provide a pulp vitality probe of sufficiently broad application for use in general dental practice. There are published indications that optical probes can be useful in juvenile and young adult human subjects, and there may be other methods of signal interpretation than those we evaluated, which would extend the use of optical probes to older subjects. We hope that some of the ways of thinking about optical probing 
that we have introduced in this paper will be of use to other researchers.

\section{Acknowledgment}

Professors Leif Olgart and Lennart Edwall and Dr. Bertil Gazelius of the Karolinska Institute, and Professor Bruce Matthews and his students Tim Amess and David Andrew of the University of Bristol gave generously of their time and knowledge to help us understand earlier work in this field. Professor Matthews also contributed a detailed and helpful critique of a draft of this paper.

Professors Harold Goodis and Rory Hume of the University of California at San Francisco offered valuable advice and encouragement in the crucial early stages of our project.

\section{REFERENCES}

1. B. Gazelius, L. Olgart, and B. Edwall, "Restored vitality in luxated teeth assessed by laser Doppler flowmeter," Endod. Dent. Traumatol. 4, 265-268 (1988).

2. S. Seltzer, I. B. Bender, and M. Ziontz, "The dynamics of pulp inflammation: correlations between diagnostic data and actual histologic findings in the pulp," Oral. Surg. 16, 846-871 and 969-977 (1963).

3. D. D. Upthegrove, J. G. Bishop, and H. L. Dorman, "A method of detection of blood flow in the dental pulp," $J$. Dent. Res. 45(4), 1115-1119 (1966).

4. S. Kobo, "Photoelectric plethysmography of dental pulp in human teeth," DMD thesis, Hebrew University, Jerusalem (1964).

5. I. Shoher, Y. Mahler, and S. Samueloff, "Dental pulp photoplethysmography in human beings," Oral Surg. 36(6), 915-921 (1973).

6. J. M. Schmitt, R. L. Webber, and E. C. Walker, "Optical determination of dental pulp vitality," IEEE Trans. Biomed. Eng. 38(4), 346-352 (1991).

7. M. Ikawa, H. Horiuchi, and K. Ikawa, "Optical characteristics of human extracted teeth and the possible application of photoplethysmography to the human pulp," Archs. Oral. Biol. 39(10), 821-827 (1994).

8. S. Kim, "Microcirculation in the dental pulp," in Experimental Endodontics, L. S. W. Spangberg, Ed., pp. 51-76, CRC Press, Boca Raton, FL (1990).

9. H. J. Van Hassel, "Physiology of the human dental pulp," Oral. Surg. 32(1), 126 (1971).

10. A. V. J. Challoner, "Photoelectric plethysmography for estimating cutaneous blood flow," in Noninvasive Physiological Measurements, Vol. 1, P. Rolfe, Ed., pp. 125-151, Academic Press, London (1979).

11. L.-G. Lindberg, "Photoplethysmography: methodological studies and applications," PhD diss., Department of Biomedical Engineering, Linköping University, Linköping, Sweden (1991)

12. L.-G. Lindberg, P. Sveider, and P. Å. Öberg, "Optical properties of blood in motion," Proc. SPIE 1649, 116-122 (1992).

13. M. Yelderman and J. Corenman, "Real time oximetry," in Computing in Anesthesia and Intensive Care, O. Prakash, S. H. Mey, and R. W. Patterson, Eds., pp. 328-341, Martinus Nijhoff, The Hague (1983).

14. D. Spitzer and J. T. ten Bosch, "The absorption and scattering of light in bovine and human dental enamel," Calcif. Tissue. Res. 17(2), 129-137 (1975).

15. W. D. Cook and D. C. McAree, "Optical properties of esthetic restorative materials and natural dentition," J. Biomed. Mater. Res. 19(5), 469-488 (1985).

16. J. J. ten Bosch and J. C. Coops, "Tooth color and reflectance as related to light scattering and enamel hardness," J. Dent. Res. 74(1), 374-380 (1995).

17. D. Fried, R. E. Glena, J. D. B. Featherstone, and W. Seka, "Nature of light scattering in dental enamel and dentin at visible and near-infrared wavelengths," Appl. Opt. 34(7), 1278-1285 (1995).

18. A. P. Sheperd and P. Å. Öberg (Eds.), Laser-Doppler Blood Flowmetry, Kluwer Academic Publishers, Dordrecht (1990).

19. B. Gazelius, L. Olgart, B. Edwall, and L. Edwall, "Noninvasive recordings of blood flow in human dental pulp," Endod. Dent. Traumatol. 2, 219-221 (1986).

20. H. Pettersson and P. Å. Öberg, "Pulp blood flow assessment in human teeth by laser doppler flowmetry," Proc. SPIE 1424, 116-119 (1991).

21. L. Olgart, "Le Fluxmetre laser Doppler dans le test de vitalité pulpaire," Realites Cliniques 5(3), 283-291 (1994).

22. J. M. Schnettler and J. A. Wallace, "Tooth vitality probe and process," U.S. Patent 5,259,761 (1993).

23. W. G. Zijlstra, A. Buursma, and W. P. Meeuwsen-van der Roest, "Absorption spectra of human fetal and adult oxyhemoglobin, de-oxyhemoglobin, carboxyhemoglobin, and methemoglobin," Clin. Chem. 37(9), 1633-1638 (1991).

24. T. R. Amess, D. Andrew, H. Son, and B. Matthews, "The contribution of periodontal and gingival tissues to the laser Doppler blood flow signal recorded from human teeth," $J$. Physiol. (Lond.) 473, 142P (1993).

25. B. Matthews, private communication.

26. H. Son and B. Matthews, "Improvements in methods for recording pulpal blood flow from human teeth with a laser Doppler flowmeter," J. Physiol. (Lond.) 476, 6P (1994).

27. B. Edwall, B. Gazelius, J.-O. Berg, L. Edwall, K. Hellander, and L. Olgart, "Blood flow changes in the dental pulp of the cat and rat measured simultaneously by laser Doppler flowmetry and local 125I clearance," Acta. Physiol. Scand. 131, 81-91 (1987).

28. T. R. Amess, D. Andrew, H. Son, and B. Matthews, "Methods for laser Doppler recording of pulpal blood flow," J. Dent. Res. 73, 287 (1994).

29. D. B. Gibbon (1966), "Psychophysiology of the oral cavity," J. Dent. Res. 45(6 Suppl.), 1627-1636.

30. T. Sasano, S. Kuriwada, N. Shoji, D. Sanjo, H. Izumi, and K. Karita, "Axon reflex vasodilatation in cat dental pulp elicited by noxious stimulation of the gingiva," J. Dent. Res. 73(12), 1797-1802 (1994).

31. N. Vongsavan and B. Matthews, "Effects of electrical stimulation of teeth on blood flow in dental pulp in man," $J$. Physiol. (Lond.) 452, 171P (1992).

32. T. R. Pitt Ford, M. A. Seare, and F. McDonald, "Action of adrenaline on the effect of dental local anaesthetic solutions," Endod. Dent. Traumatol. 9(1), 31-35 (1993).

33. T. M. Odor, T. R. Pitt Ford, and F. McDonald, "Effect of inferior alveolar nerve block anaesthesia on the lower teeth," Endod. Dent. Traumatol. 10(3), 144-148 (1994).

34. T. M. Odor, T. R. Pitt Ford, and F. McDonald, "Adrenaline in local anaesthesia: the effect of concentration on dental pulpal circulation and anaesthesia," Endod. Dent. Traumatol. 10(4), 167-173 (1994).

35. S. Hellem, L. S. Jakobsson, G. E. Nilsson, and D. H. Lewis, "Measurement of micro-vascular blood flow in cancellous bone using laser Doppler flowmetry and 133Xe-clearance," Int. J. Oral. Surg. 12, 165-177 (1983).

36. H. Packman, I. Shoher, and R. S. Stein, "Vascular responses in the human periodontal ligament and alveolar bone detected by photoelectric plethysmography: the effect of force application to the tooth," J. Periodontol. 48(4), 194-200 (1977).

37. B. Matthews and N. Vongsavan, "The origin of laser Doppler blood flows records obtained from intact teeth," J. Dent. Res. 70, 720 (1991).

38. S. Soo-Ampon, N. Vongsavan, M. Soo-Ampon, W. Apai, and B. Matthews, "The sources of laser Doppler bloodflow signals from human teeth," J. Dent. Res. 75, 279 (1996).

39. D. S. Ramsay, J. Årtun, and S. S. Martinen, "Reliability of pulpal blood-flow measurements utilizing laser Doppler flowmetry,"' J. Dent. Res. 70(11), 1427-1430 (1991).

40. AE. R. Ingólfsson, L. Tronstad, E. V. Hersh, and C. E. Riva, "Effect of probe design on the suitability of laser Doppler flowmetry in vitality testing of human teeth," Endod. Dent. Traumatol. 9(2), 65-70 (1993).

41. G. H. Weiss, R. Nossal, and R. F. Bonner, "Statistics of pen- 
etration depth of photons re-emitted from irradiated tissue," J. Modern Opt. 36(3), 349-359 (1989).

42. G. H. Heithersay and R. S. Hirsch, "Tooth discoloration and resolution following a luxation injury: significance of blood pigment in dentin to laser Doppler flowmetry readings," Quintessence. Int. 24(9), 669-676 (1993).

43. F. McDonald and T. R. Pitt Ford, "Blood flow changes in permanent maxillary canines during retraction," Eur. J. Orthod. 16(1), 1-9 (1994).

44. K. Hertrich and W. H. Raab, "Reaktive Änderung der parodontalen Mikrozirkulation bei kieferorthopädischen Kräften," Fortschr. Kieferorthop. 51(5), 253-258 (1990).

45. Perimed, Literature reference list no. 12, Perimed AB, Järfälla, Sweden (1994).

46. N. Vongsavan and B. Matthews, "Experiments in pigs on the sources of laser Doppler blood-flow signals recorded from teeth," Archs. Oral Biol. 41(1), 97-103 (1996).

47. B. Gazelius, private communication.

48. L. Olgart, B. Gazelius, and U. Lindh-Strömberg, "Laser Doppler flowmetry in assessing vitality in luxated permanent teeth," Int. Endod. J. 21(5), 300-306 (1988).

49. W. H.-M. Raab, K. Reithmayer, and P. Grund, "Die Vitalitätsprüfung der Zahnpulpa mit der Laser-Doppler-
Flussmessung," Dtsch. Zahnarztl. Z. 45(11), 725-727 (1990).

50. C. M. Hill, "The efficacy of transillumination in vitality tests," Int. Endod. J. 19(4), 198-201 (1986).

51. A. H. Rowe and T. R. Pitt Ford, "The assessment of pulpal vitality," Int. Endod. J. 23(2), 77-83 (1990).

52. B. Gazelius, U. Stromberg-Lindh, and B. Mejare, "Laser Doppler (LD) in pulp diagnosis of teeth exposed to different kinds of trauma," Endod. Dent. Traumatol. 10, 41 (1994).

53. D. J. Kenny, R. D. Fratkin, and D. H. Johnston, "Evaluation of a laser Doppler flowmeter for vitality testing primary maxillary anterior teeth," Endod. Dent. Traumatol. 10, 42 (1994).

54. R. Nissan, M. Trope, C.-D. Zhang, and B. Chance, "Dual wavelength spectrophotometry as a diagnostic test of the pulp chamber contents," Oral. Surg. Oral. Med. Oral. Pathol. 74(4), 508-514 (1992).

55. M. R. Robinson, R. P. Eaton, D. Haaland, G. W. Koepp, E. V. Thomas, B. R. Stallard, and P. L. Robinson, "Noninvasive glucose monitoring in diabetic patients: a preliminary evaluation," Clin. Chem. 38(9), 1618-1622 (1992).

56. A. Hartmann, J. Azérad, and Y. Boucher, "Environmental effects of laser Doppler pulpal blood-flow measurements in man," Arch. Oral. Biol. 41(4), 333-339 (1996). 